\title{
Significantly Enhanced Electrical Performances of Eco-Friendly Dielectric Liquids for Harsh Conditions with Fullerene
}

\author{
Zhengyong Huang ${ }^{1,2}$, Feipeng Wang ${ }^{1, *}{ }^{1}$, Qiang Wang ${ }^{3}$, Wei Yao ${ }^{1}$, Kai Sun ${ }^{3}$, Ruiqi Zhang ${ }^{1}$, \\ Jianying Zhao ${ }^{1}$, Ziyi Lou ${ }^{1}$ and Jian $\mathrm{Li}^{1, *}$ \\ 1 State Key Laboratory of Power Transmission Equipment and System Security and New Technology, \\ Chongqing University, Chongqing 400044, China \\ 2 Postdoctoral Research Station on Chemical Engineering and Technology, Chongqing University, \\ Chongqing 400040, China \\ 3 State Grid Chongqing Electric Power Company, Chongqing 401123, China \\ * $\quad$ Correspondence: fpwang@cqu.edu.cn (F.W.); lijian@cqu.edu.cn (J.L.); Tel.: +86-18580768887 (F.W.)
}

Received: 28 May 2019; Accepted: 3 July 2019; Published: 9 July 2019

\begin{abstract}
The eco-friendly vegetable liquid is increasingly used because of the growing demand for environmentally friendly dielectric liquid. A vegetable liquid/fullerene nanofluid was fabricated via ultrasonic processing with good dispersion of the fullerene nanoparticles. It was observed that a small amount of fullerene $(\sim 100 \mathrm{mg} / \mathrm{L})$ can significantly improve the electrical properties of vegetable insulating liquid (dissipation factor decreased by $20.1 \%$, volume resistivity increased by 23.3\%, and Alternating Current (AC) dielectric breakdown strength increased by 8.6\%). Meanwhile, the trace amount of fullerene is also able to improve the electrical performances (i.e., dissipation factor and electrical resistivity) of the vegetable nanofluid under harsh conditions of long-term thermal aging compared with the blank contrast. The reduced acid values (25\%) and dissolved decomposition gases (58.2\% for hydrogen) in the aged vegetable nanofluid indicate the inhibition of molecule decomposition of vegetable liquid with fullerene. The improved electrical performances and thermal resistance of the vegetable nanofluid contribute to the electron affinity of fullerene proved by calculation of electron density distribution on the surface. The thermogravimetric analysis of the nanofluid under different atmospheres interprets that the oxygen absorbed inevitably in the fullerene contributes to the performance deterioration of the nanofluids during the initial aging. This work provides a potential method towards eco-friendly dielectric liquid with great electrical performances for harsh environments.
\end{abstract}

Keywords: eco-friendly; dielectric liquids; fullerene; electrical performance

\section{Introduction}

Liquid dielectric, which is a self-healing dielectric material in a liquid state, is widely used as dielectric materials in capacitors [1,2] and cables [3], and as an insulating coolant in transformers [4] and switchgears [5] for the non-permanent conductive trace in the fluid in the discharge channel. To further reduce the fire risk from the liquid dielectric and improve the reliability and eco-friendliness of the insulating facility, researchers are pursuing eco-friendly liquid dielectric with superior electrical performances from the natural resources, such as natural esters [6,7]. The electrical properties of the eco-friendly liquid dielectric generally include dissipation factors, volume resistivity and dielectric breakdown strength [8]. The electrical properties tend to be strongly influenced by dissolved gases, dust, and especially ionic impurities such as acidic material [9]. Recently, some studies have reported that the incorporation of inorganic nanoparticles into natural esters can greatly improve the electrical 
performances of liquid dielectric materials [10-13]. Given the extremely high specific surface area and reactivity, a few nanoparticles can absorb the reactive oxygen species produced during the aging of vegetable insulating liquid and inhibit its oxidation. Meanwhile, nanoparticles adsorbed the moisture reduced the hydrolysis of ester molecules and improved the anti-aging effect of oil-paper insulation [14].

Nevertheless, it is worth noting that the dispersibility of magnetic nanoparticles was greatly influenced by orientation of the external magnetic field [15]. In magnetic fields, the magnetic particles aggregation led to the formation of the bridge across the gap between the electrodes, which lowered the dielectric breakdown voltage and was not propitious for wide use in transformers [16]. There exists the influence of magnetic fields on dielectric properties in the ester nanofluids modified by conductive nanoparticles [17]. Thus, the overall electrical performances of the modified liquid dielectric may not be improved $[18,19]$. Furthermore, because of the high ratio of inorganic nanoparticle fillers, the biodegradability of the natural esters has been much lower than the fresh natural esters $[20,21]$. Therefore, the basic advantage of natural esters being renewable disappears. This restricts extensive applications of natural materials in electrical and electronic industries. Thus, an eco-friendly liquid nanodielectric with overall improved electrical performances and lower filler concentration under harsh conditions is highly desired.

Fullerene with unique physico-chemical properties [22] have been widely investigated as multifunctional materials for applications in tissue engineering [23], photovoltaics [24], molecular imaging, and bio-sensing $[25,26]$. Specifically, it has been proved that the addition of fullerene $\mathrm{C}_{60}$ to mineral oil enhances the resistivity by $20-30 \%$ and reduces the dielectric loss by one to two orders of magnitude [27-29].

In this study, it is demonstrated for the first time that a small amount of fullerene $(\sim 100 \mathrm{mg} / \mathrm{L})$ significantly improves all the electrical properties of vegetable insulating liquid (Refinement Bleaching and Distillation (RDB)) under harsh conditions of long-term thermal aging compared with the blank contrast. The reduced acid values (25\%) and dissolved decomposition gases ( $58.2 \%$ for hydrogen) in the aged vegetable nanofluid (fullerene RDB nanofluid) indicate the inhibition of molecule decomposition of vegetable liquid with fullerene. The improved electrical performances of the vegetable nanofluid under thermal aging contribute to the electron affinity of fullerene. The thermogravimetric analysis of the nanofluids under different atmospheres indicates that the oxygen absorbed inevitably in the fullerene contributes to the performance deterioration of the nanofluids during initial aging. This work provides a potential method towards eco-friendly dielectric liquid with great electrical performances for harsh environments.

\section{Experimental}

\subsection{Preparation of $\mathrm{C}_{60}$ Nanofluid}

Firstly, $0.5 \mathrm{~g}$ of oleic acid was taken and a small amount of anhydrous ethanol was mixed with $\mathrm{C}_{60}$ and mechanically stirred for $2 \mathrm{~h}$ to maintain ultrasonic dispersion. The ultrasound energy was $455 \mathrm{~W}$ and the ultrasonic process was a circulation of a $2 \mathrm{~s}$ pause and a $2 \mathrm{~s}$ operation. Secondly, it was cooled to room temperature and subsequently centrifuged for $3000 \mathrm{rpm}$ and washed with ethanol and cyclohexane several times to remove the residual unreactive oleic acids on the surface of $\mathrm{C}_{60}$. Thirdly, the mixed liquor was placed into the vacuum drying oven at $60{ }^{\circ} \mathrm{C}$, and the vacuum degree was maintained at $0.1 \mathrm{MPa}$ for $12 \mathrm{~h}$. Finally, the modified $\mathrm{C}_{60}$ nanoparticles were prepared and reserved.

The vegetable liquids (RDB obtained from raw rapeseed oil by three procedures, alkaline refinement, vacuum distillation, and bleaching in Chongqing University [30]) and mineral liquids (25\# from Karamay, Xinjiang, China) were dried under a pressure of $0.1 \mathrm{MPa}$ for $72 \mathrm{~h}$ at $60^{\circ} \mathrm{C}$. The nanoparticles were added to two insulating liquids at the concentration of $0,50,100,200$, and $300 \mathrm{mg} / \mathrm{L}$. The $\mathrm{C}_{60}$ nano-modified insulating liquid was ultrasonically agitated for $20 \mathrm{~min}$ at $30^{\circ} \mathrm{C}$ to uniformly disperse nanoparticles in the liquid. 


\subsection{Electrical Test}

Different concentrations of $\mathrm{C}_{60}$ modified insulating liquid also present different performances. In this paper, the properties of vegetable liquid (RDB oil) were measured by an authorized testing institute in China, applying Chinese testing standards in accordance with the International Electro-technical Commission (IEC) and International Organization for Standardization (ISO) [30]. Particularly, the measurement of dielectric loss and electrical resistivity were performed using BAURDLTC dissipation factor measurement equipment, followed by the execution of IEC 60247. The measurement of AC breakdown voltage was performed using flat spark gap at ambient temperatures and AC voltage with a frequency of $50 \mathrm{~Hz}$. A $2.5 \mathrm{~mm}$ spark gap was used in the test. The measurement of lightning impulse breakdown voltage followed IEC 60897, and a 15-mm needle-sphere spark gap was used. Each measurement was carried out five times, and the arithmetic mean was obtained.

\subsection{Thermal Aging Test}

According to IEC 61125A, the thermal aging speed was doubled when the aging temperature of the insulation liquid was increased by $6{ }^{\circ} \mathrm{C}$. This study analyzed the nanofluid samples without $\mathrm{C}_{60}$ after aging. A total of 28 samples were analyzed using different aging times $(0,6,12,18,24$, 30 , and 36 days), and various concentrations of $\mathrm{C}_{60}(0,50,100$ and $200 \mathrm{mg} / \mathrm{L})$ accelerated aging of the samples at $130^{\circ} \mathrm{C}$. Firstly, the $\mathrm{C}_{60}$ nano-modified vegetable insulating liquid was dried under a pressure of $-0.1 \mathrm{MPa}$ for $48 \mathrm{~h}$ at $90^{\circ} \mathrm{C}$. Secondly, when the sample was cooled to room temperature, the samples were packed into a conical flask, and most of the air in the bottle was discharged by nitrogen. Finally, glass bottle stoppers were used to seal the sample bottles after the injection of nitrogen, and the bottles were wrapped with PMP(Poly(4-methylpentene-1)) polyethylene film and aluminium foil. The PMP polyethylene film is utilized to ensure the isolation of nanofluids with the oxygen in the air during the aging process and to keep the thermal aging of nanofluids under the nitrogen atmosphere. The aluminium foil was chosen to prevent the nanofluids from the light irradiation because of the strong photosensitivity of the $\mathrm{C}_{60}$ nanoparticles.

\subsection{Simulation of Electron Density Distribution of $C_{60}$}

The electron density distribution of $\mathrm{C}_{60}$ was calculated by software Gaussian 09W (Gaussian Inc., Wallingford, CT, USA), which specializes in chemical analysis. Then, the graphical result of the electron density distribution was shown by using software of Gauss View.

\section{Results and Discussion}

\subsection{Characterization of Nanofluids}

Although $\mathrm{C}_{60}$ have minimal solubility in organic solvents, the extremely small particle size of its nanoparticles has a large specific surface area with high surface energy, which leads to agglomeration. Thus, oleic acid was used in this experiment to modify the surface of $\mathrm{C}_{60}$ nanoparticles, thereby enhancing dispersibility and stability of $\mathrm{C}_{60}$ in insulating liquid.

Figure 1 shows the infrared spectroscopy pattern (test by Thermo Fisher NICOLET IS10, Shanghai, China) of $C_{60}$ nanoparticles. The characteristic peaks of $C_{60}$ were clearly indicated at 524, 574, 1182, and $1428 \mathrm{~cm}^{-1}$ and peaks at 524 and $574 \mathrm{~cm}^{-1}$ were most evident, which was assigned to the four main Infrared(IR) bands, dipole-active vibrational modes with $\mathrm{F}_{\text {lu }}$ symmetry, of $\mathrm{C}_{60}$ molecule [31]. The vibration peaks at 2850 and $2919 \mathrm{~cm}^{-1}$ were absorbed by saturated hydrocarbon $\left(-\mathrm{CH}_{3}\right.$ and $\left.-\mathrm{CH}_{2}\right)$ of oleic acid molecules. Moreover, the peak of carboxylate, which was in the range of $1540 \mathrm{~cm}^{-1}$, indicated the presence of oleic acid around the nanoparticles, and the peak of $\mathrm{CO}_{2}$ was also evident [32]. 


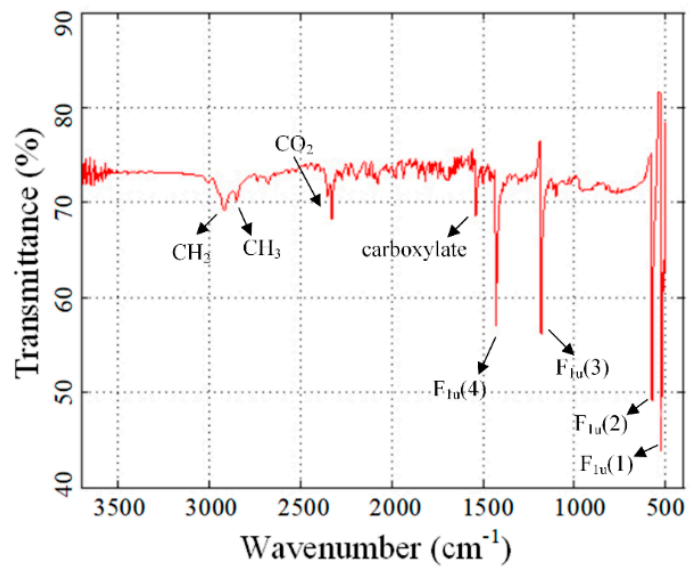

Figure 1. Infrared spectroscopy of the $\mathrm{C}_{60}$ nanoparticles.

Figure 2 shows the X-ray diffraction (XRD test by Shimazu XRD-6000, $\mathrm{Cu}-\mathrm{K} \alpha$ ) of $\mathrm{C}_{60}$ and the peak effect of its size and shape. The size of the nanoparticles was calculated using the Scherrer Equation [33]:

$$
D=\frac{K \cdot \lambda}{\beta \cdot \cos \theta}
$$

where $D$ is the size of a crystal particle, $\beta$ is the half-width of diffraction peak, $\theta$ is the diffraction angle of $X$-ray, and $K$ is constant with a value of 0.89 . The result showed the size of $C_{60}$ crystal particle at a point with $4 \mathrm{~nm}$ to $6 \mathrm{~nm}$. Table 1 shows the basic physical and chemical properties of pure vegetable insulating liquid (RDB fabricated by Chongqing University [30]) and mineral liquid (25\# from Karamay, Xinjiang). The nanofluids are expected to be processed away from light due to the photosensitivity of $\mathrm{C}_{60}$. The double bond of the carbon in $\mathrm{C}_{60}$ molecule can be opened in certain light conditions, and then adjacent $\mathrm{C}_{60}$ molecules might be linked by new covalent bonds [34]. This characteristic may cause the unsatisfactory modification and dissolution of $\mathrm{C}_{60}$ nanoparticles.

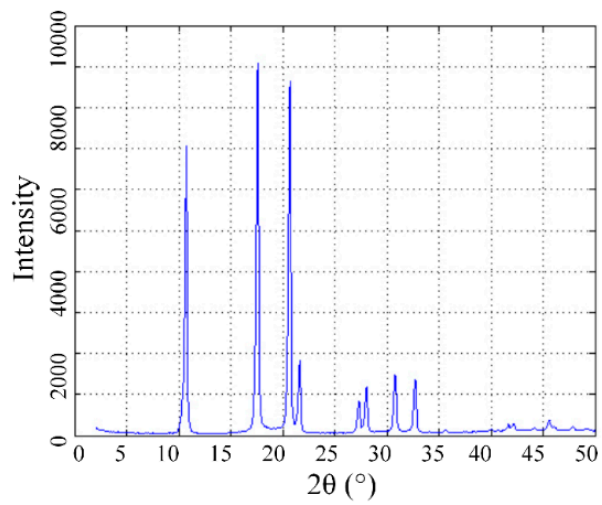

Figure 2. X-ray diffraction pattern of $\mathrm{C}_{60}$ after surface modification.

Table 1. Basic physicochemical properties of insulating liquid.

\begin{tabular}{cccc}
\hline \multirow{2}{*}{ Parameters } & Unit Symbol & \multicolumn{2}{c}{ Typical Value } \\
\cline { 3 - 4 } & & Vegetable Liquid & Mineral Liquid \\
\hline Kinematic Viscosity at $40{ }^{\circ} \mathrm{C}$ & $\mathrm{mm}^{2} \cdot \mathrm{s}^{-1}$ & 41.0 & 10.0 \\
Density at $20{ }^{\circ} \mathrm{C}$ & $\mathrm{kg} \cdot \mathrm{m}^{-3}$ & 0.90 & $0.83-0.89$ \\
Flash Point & ${ }^{\circ} \mathrm{C}$ & 320 & $\geq 135$ \\
Pour Point & ${ }^{\circ} \mathrm{C}$ & -18 & -22 \\
Acid Value & $\mathrm{mgKOH} \cdot \mathrm{g}^{-1}$ & $\leq 0.03$ & $\leq 0.01$ \\
\hline
\end{tabular}


The zeta potential of $\mathrm{C}_{60}$ modified insulating liquids was tested. Zeta potential is an important characterization of the stability of a dispersion system. The absolute value of zeta potential of a stable dispersion system requires at least $30 \mathrm{mV}$. The result showed that the zeta potential of $300 \mathrm{mg} / \mathrm{L}$ concentration of $\mathrm{C}_{60}$ nanoparticles for vegetable insulating and mineral liquids was $-45.7 \mathrm{mV}$ and $39.4 \mathrm{mV}$, respectively, thereby indicating that the modified $\mathrm{C}_{60}$ nanoparticles in insulating liquid were stabilized. The nanofluids with different concentrations of $\mathrm{C}_{60}(50-300 \mathrm{mg} / \mathrm{L})$ were stable and without sediment even after 12 months.

\subsection{Dielectric Loss and Electrical Resistivity}

The dielectric dissipation factor and electrical resistivity can effectively reflect the degradation and contamination of insulating liquids. Figure 3 shows that the dissipation factor and electrical resistivity of nanofluids changed with different concentrations of $\mathrm{C}_{60}$, and the measured results of vegetable liquid varied a little greater than mineral liquid. For vegetable liquid, the greatest variation in the dissipation factor and electrical resistivity occurred at $0 \mathrm{mg} / \mathrm{L}$ and $50 \mathrm{mg} / \mathrm{L}$, respectively. As for mineral liquid, the greatest variation in the dissipation factor and electrical resistivity occurred at $250 \mathrm{mg} / \mathrm{L}$ and $50 \mathrm{mg} / \mathrm{L}$, respectively. Figure 3a shows that the dissipation factor of the vegetable insulating liquid significantly decreased at a low concentration from $50 \mathrm{mg} / \mathrm{L}$ to $150 \mathrm{mg} / \mathrm{L}$, and then returned to the situation of the pure sample. The largest drop appeared in $100 \mathrm{mg} / \mathrm{L}$ concentration of $\mathrm{C}_{60}$, which shows an approximate decline of $20.1 \%$. The experimental data evidently showed that the electrical resistivity of nanofluid increased after $\mathrm{C}_{60}$ adjunction. The overall trend exhibited a decrease after the first increase, followed by the increasing concentration of $\mathrm{C}_{60}$. The electrical resistivity of vegetable insulating liquid obtained the maximum upgrade at the concentration of $100 \mathrm{mg} / \mathrm{L}$, which showed an approximate increase of $23.3 \%$. Although the concentration reached up to $300 \mathrm{mg} / \mathrm{L}$, electrical resistivity also increased to nearly $1.3 \times 10^{10} \Omega \cdot \mathrm{m}$.

Figure $3 \mathrm{~b}$ shows that the addition of $\mathrm{C}_{60}$ nanoparticles would not have a significant effect, except at $50 \mathrm{mg} / \mathrm{L}$. This result was evident due to the low dissipation factor resistivity of mineral liquid. However, the electrical resistivity of mineral based nanofluid decreased significantly when the concentration was greater than $50 \mathrm{mg} / \mathrm{L}$. Thereby, addition of $\mathrm{C}_{60}$ nanoparticles in liquid can improve the dielectric properties for vegetable insulating liquid, while it does not change obviously for mineral liquid.
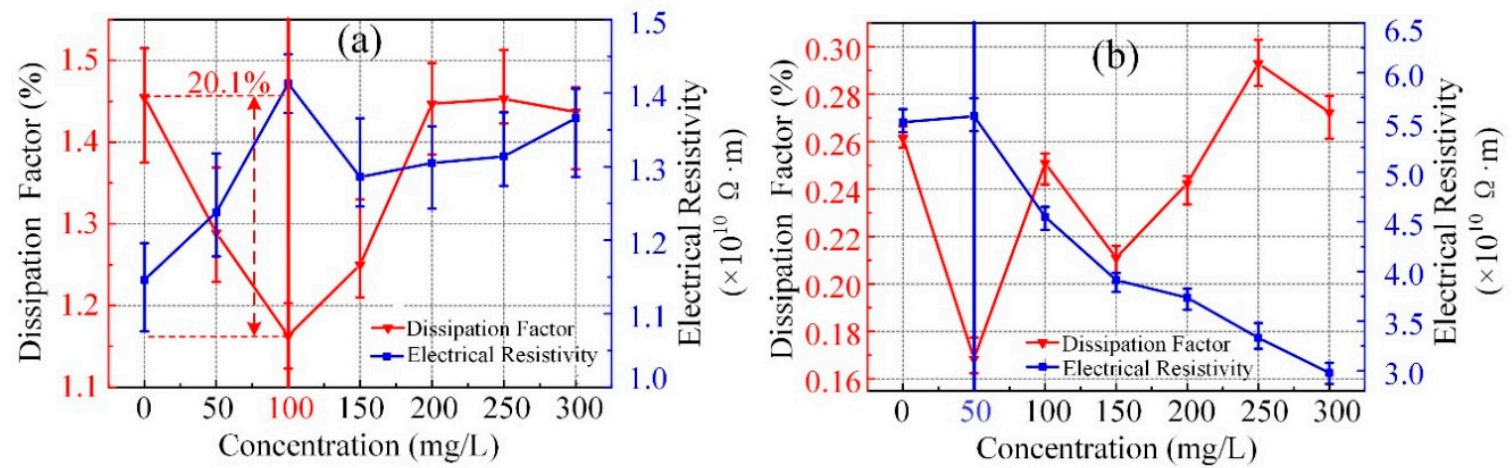

Figure 3. The variation of the dissipation factor and electrical resistivity with $\mathrm{C}_{60}$ concentrations of vegetable insulating liquid (a) and mineral liquid (b).

\subsection{Dielectric Breakdown Strength}

AC breakdown voltage is an important parameter that characterizes the dielectric strength of the liquid medium. Figure 4 shows that the AC breakdown voltage of nanofluid varied with different $\mathrm{C}_{60}$ concentrations, and the measurement of vegetable liquid varied a little greater than mineral liquid, consistent to electrical resistivity and the dissipation factor. The greatest variation of AC breakdown voltage of vegetable liquid occurred at $0 \mathrm{mg} / \mathrm{L}$, and that of mineral liquid occurred at $150 \mathrm{mg} / \mathrm{L}$. The breakdown voltage may not be negatively affected due to the doped $\mathrm{C}_{60}$ into the 
vegetable insulating liquid. The AC breakdown voltage slightly increased at low concentrations and then significantly declined. The AC breakdown voltage obtained the most improvement with an increase of approximately $8.6 \%$ at $100 \mathrm{mg} / \mathrm{L}$ concentration of $\mathrm{C}_{60}$. The breakdown voltage decreased by $11.3 \%$ compared to pure liquid following the increasing concentration. However, mineral liquid obtained the most improvement at approximately $21.7 \%$ at $200 \mathrm{mg} / \mathrm{L}$ concentration of $\mathrm{C}_{60}$. The result indicates that modified vegetable insulating liquid can obtain the optimal dielectric properties and the AC breakdown characteristic at $100 \mathrm{mg} / \mathrm{L}$ concentration of $\mathrm{C}_{60}$.

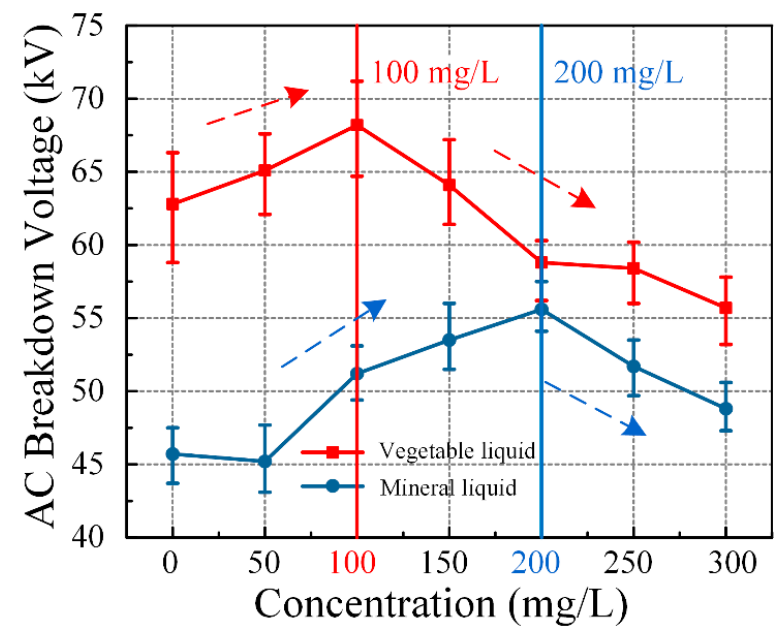

Figure 4. The variation of $\mathrm{AC}$ breakdown voltage with $\mathrm{C}_{60}$ concentrations of vegetable insulating liquid and mineral liquid.

Table 2 shows the lightning impulse breakdown voltage of nanofluids with $100 \mathrm{mg} / \mathrm{L} \mathrm{C}_{60}$ nanoparticles. The lightning impulse breakdown voltage was enhanced to a certain extent. Given the addition of $\mathrm{C}_{60}$ nanoparticles, positive lightning breakdown voltage increased by approximately $7.3 \%$, and the percentage of negative lightning breakdown voltage was $7.4 \%$ greater than vegetable insulating liquid. As a control for mineral liquid, the lightning impulse breakdown voltage of the mineral insulating liquid was simultaneously promoted through the modification of $\mathrm{C}_{60}$ nanoparticles. The positive and negative breakdown voltages increased by $10.0 \%$ and $7.6 \%$, respectively.

Table 2. Lightning impulse breakdown voltage of insulating liquid.

\begin{tabular}{ccccc}
\hline \multirow{2}{*}{ Liquid Types } & \multicolumn{2}{c}{ Breakdown Voltage (kV) } & \multicolumn{2}{c}{ Breakdown Time $(\boldsymbol{\mu s})$} \\
\cline { 2 - 5 } & Positive & Negative & Positive & Negative \\
\hline Vegetable Liquid & 78.2 & 83.7 & 10.3 & 11.9 \\
Nano Vegetable Liquid & 83.9 & 89.9 & 10.9 & 12.3 \\
Mineral Liquid & 60.8 & 103.3 & 8.7 & 11.1 \\
Nano Mineral Liquid & 66.9 & 111.2 & 9.2 & 11.9 \\
\hline
\end{tabular}

The breakdown characteristics of modified insulating liquid with $\mathrm{C}_{60}$ under $\mathrm{AC}$ and impulse voltage can be unified into the streamer development $[35,36]$. In the development of the streamer of nanofluids, electron mobility is much faster than the positive ion mobility. Nanoparticles can adsorb the fast electrons and convert them into slower negative charges, which results in reducing the development of the head development rate of the streamer. Thus, this weakens the electric field strength of the head and meanwhile reduces the rate of positive and negative charge movement. Finally, the breakdown voltage and the breakdown time increased. 
The time of the electron is captured by nanoparticles in the transformer liquid calculated as [36]:

$$
\tau=\frac{2 \varepsilon_{b f}+\varepsilon_{n p}}{2 \sigma_{n f}+\sigma_{n p}}
$$

where $\varepsilon_{b f}$ and $\varepsilon_{n p}$ are relative dielectric constant of insulating liquids and nanoparticles, respectively. $\sigma_{n f}$ and $\sigma_{n p}$ are the electrical conductivity of nanofluids and nanoparticles, respectively. Due to the time of the streamer development in insulating liquids is in microseconds, it can be considered that when the relaxation time of the nanoparticle is far less than the microsecond level, electrons can be trapped during the development of the streamer, thereby inhibiting the streamer development $[37,38]$.

As the semiconductor material of $\mathrm{C}_{60}$ nanoparticles, the charge distribution is generated on its surface under an electric field. The presence of a surface charge could result in the spatial potential to occur with redistribution around the center of nanoparticles. The model of potentials generated by the spherical charges of nanoparticles in Figure 5 can be expressed by:

$$
\delta=\varepsilon_{0} E_{0}\left(\frac{\varepsilon_{n p}-\varepsilon_{b f}}{2 \varepsilon_{b f}+\varepsilon_{n p}}\right) \cos \varphi \sin \theta
$$

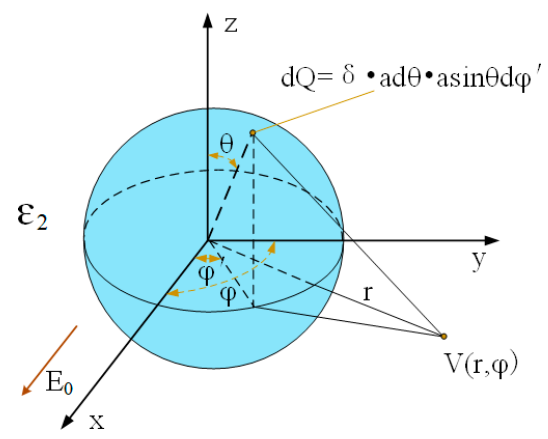

Figure 5. Surface polarization of charged nanoparticles in a continuous dielectric field.

When the direction of the external electric field is the same as the positive direction of the $\mathrm{X}$-axis, the potential distribution generated by the surface polarization of the nanoparticle is:

$$
V(r, \varphi)=\frac{a E_{0}}{4 \pi}\left(\frac{\varepsilon_{n p}-\varepsilon_{b f}}{2 \varepsilon_{b f}+\varepsilon_{n p}}\right) \times \int_{-\pi}^{\pi} \int_{0}^{\pi} \frac{\sin ^{2} \theta d \theta \cos \varphi d \varphi}{\sqrt{1+(r / a)^{2}-2(r / a) \sin \theta \cos \left(\varphi-\varphi^{\prime}\right)}}
$$

where the $E_{0}$ is the field strength, $r$ is the distance from the centre of the nanoparticles and the $a$ is radius of the nanoparticles. The results of the nano-polarization model show that the distribution of the surface potential of nanoparticles is also related to their size. Surfactants on surface of nanoparticles, which increased the effective radius of nanoparticles, were increasing the trap depth of the nanoparticles [18]. Subsequently, the potential well was prompted to deepen and increased the breakdown characteristics. However, as soon as the concentration of $\mathrm{C}_{60}$ nanoparticles increased to a certain extent, the percolation mechanism occurred; that is, the nanoparticles form the semi-conductive parts where $\mathrm{C}_{60}$ is the conductor and then reduce the breakdown strengths.

However, $\mathrm{C}_{60}$ nanoparticles also have their unique side, such as electronegativity. The $\mathrm{C}_{60}$ molecule contains 60 electrons, but its closed shell structure requires 72 electrons. Theoretical calculations show that the lowest unoccupied molecular orbital (LUMO) energy level of the $\mathrm{C}_{60}$ molecule is low and is in triple degeneration, which allows a single $\mathrm{C}_{60}$ molecule to accept at least six electrons, thereby leading to strong electronegativity [35]. Furthermore, electron affinity, which reflects the energy released by a unit atom or molecule that captures an electron, can respond to the capacity of the atom or molecule to accept electrons. The greater the affinity of the electron, the stronger is the capability 
of atoms or molecules to capture electrons. On the contrary, the electrons are more likely to escape. Moreover, if the electron affinity value is equal to or even less than zero, then the surface charge escapes at any time. At present, the electron affinity of $\mathrm{C}_{60}$ was accurately calculated by Wang et al. $(2.683 \pm 0.008 \mathrm{eV})$ [37]. $\mathrm{C}_{60}$ molecules capture free electrons to form negative ions, thereby weakening the discharge development and enhancing the breakdown strengths of vegetable insulating liquid.

\subsection{Dielectric Properties of Aging Nanofluid}

Figure 6 shows that the dissipation factor changed with the aging time of vegetable and mineral liquids with different concentrations of $\mathrm{C}_{60}$. The increase rate of dielectric loss factor of $\mathrm{C}_{60}$ modified vegetable liquid was evidently higher than pure liquid in the early stage. After 12 days of aging, the dissipation factor of the modified vegetable liquid slowly changed and the dielectric loss factor became lower than pure liquid. The dissipation factor of pure mineral liquid did not result in any significant change. However, with the addition of $\mathrm{C}_{60}$ nanoparticles in mineral liquid, the dissipation factor increased with the concentration.
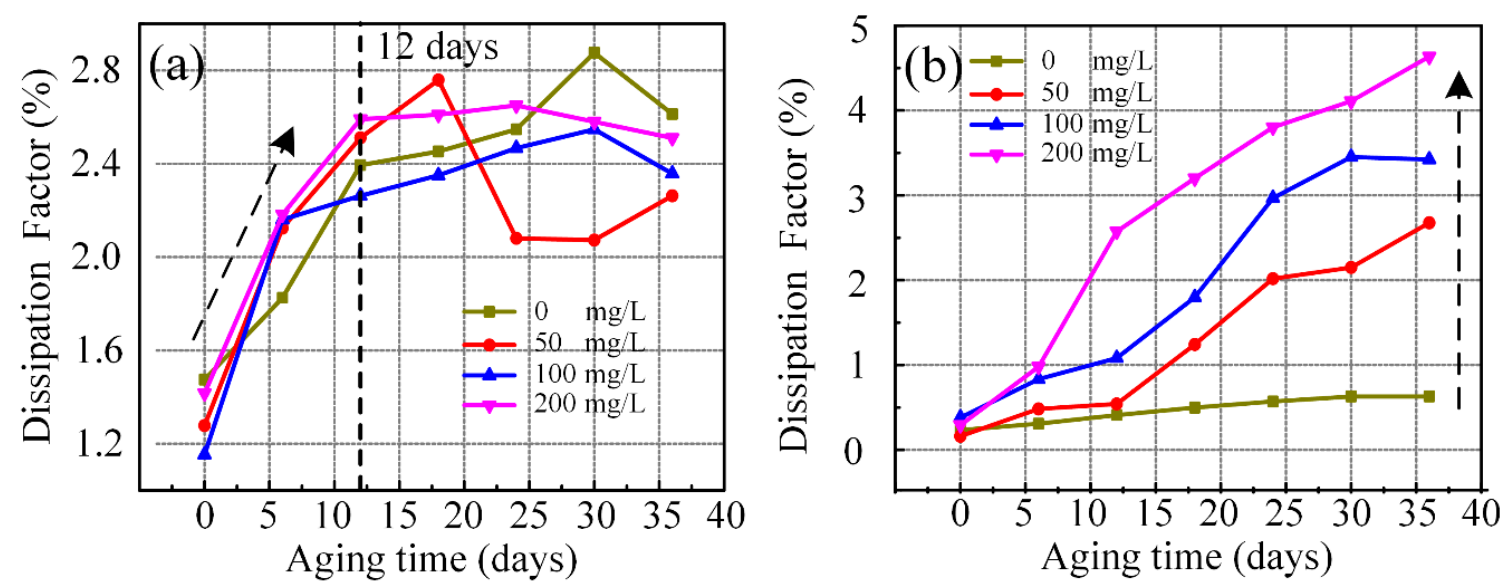

Figure 6. The variation of dissipation factor with $\mathrm{C}_{60}$ concentration of aging vegetable insulating liquid (a) and aging mineral liquid (b).

The $\mathrm{C}_{60}$ nanoparticles are able to slow down the thermal aging of the vegetable insulating liquid. However, there exist small amounts of oxygen in the $\mathrm{C}_{60}$ nanoparticles inevitably during the experiment. The traces of oxygen introduced into the vegetable insulating liquid by $\mathrm{C}_{60}$ can accelerate the cracking of the vegetable insulating liquid. At the same time, the small amount of $\mathrm{C}_{60}$ nanoparticles lead to the poor inhibition of vegetable liquid cracking and the significantly increased dielectric loss of vegetable liquid. As the thermal aging of vegetable liquid progresses, when the traces of oxygen absorbed in the $\mathrm{C}_{60}$ nanoparticles is consumed, the $\mathrm{C}_{60}$ nanoparticles without oxygen demonstrate great resistance to the cracking of vegetable liquid, resulting in the low dielectric loss of the vegetable liquid during the later aging stage.

Figure 7 shows that electrical resistivity varies with different concentrations of $C_{60}$ modified vegetable and mineral liquids. The electrical resistivity of the $\mathrm{C}_{60}$ modified vegetable liquid is higher than pure liquid in the early stage of aging. However, with the increased aging time, the addition of $\mathrm{C}_{60}$ nanoparticle reduced the value of electrical resistivity as compared to the pure liquid. 

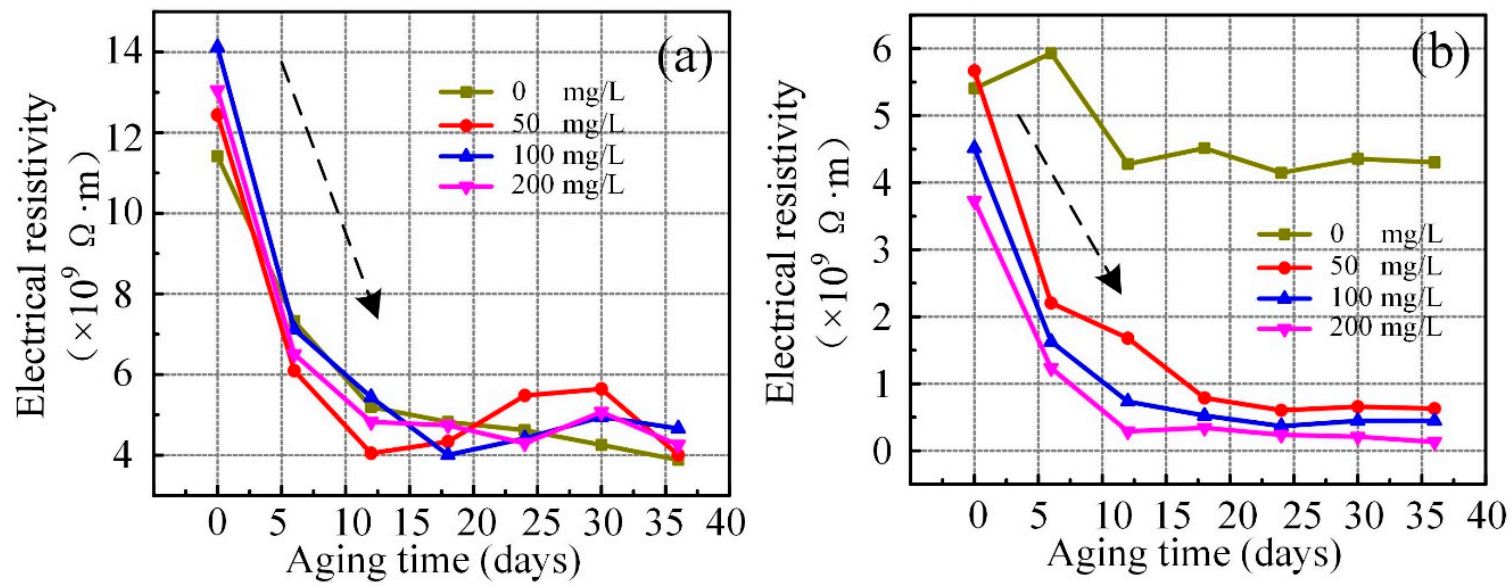

Figure 7. The variation of electrical resistivity with $\mathrm{C}_{60}$ concentration of aging vegetable insulating liquid (a) and aging mineral liquid (b).

Triglyceride, a mixture of three fatty acid molecules and one glycerol molecule, is the main component of vegetable liquid, and fatty acid molecules consist of oleic acid, linoleic acid, $\alpha$-linoleic acid, etc. Due to the sensitivity of the unsaturated double bonds of fatty acid molecules to oxygen at high temperature, the glycerol chains and the fatty acid molecules are easily oxidized and decomposed by oxygen at high temperature, thereby resulting in the generation of short-chain fatty acids, hydroxyl radicals, peroxides, ketones, aldehydes, and other substances. $\mathrm{C}_{60}$ nanoparticles as antioxidants are stronger than vitamin E composing of synthetic antioxidants, such as BHA and BHT. The addition of $\mathrm{C}_{60}$ nanoparticles to vegetable liquid can inhibit the action process of the hydroxyl radical and the hydroperoxide, thereby enhancing the oxidation resistance [38]. Unlike vegetable liquid, the mineral liquid is more difficult to shed hydrogen atoms from carbon chains due to the absence of labile double bonds. The oxidation induction period of mineral liquid is longer and the oxidation reaction is slightly intense as vegetable liquid.

\subsection{Acid Values of Aged Nanofluid}

Acid value is an important indicator to evaluate the oxidation degree of insulating liquid. Figure 8a shows that the acid value of nano vegetable liquid aging for 35 days was approximately 10 times larger than pure liquid at day 0 . Figure 8 a shows that pure liquid samples had lower acid value than $C_{60}$ doped samples in the early accelerated thermal aging stage. This phenomenon indicates that modified liquids entered the development of the thermal acidification stage earlier than the pure sample. When the acid value of pure sample accelerated significantly, the trend of the curve evidently exceeded the modified liquid samples. Moreover, when additional $C_{60}$ was added, the acid value was less after 20 days of aging. This result suggests that $C_{60}$ nanoparticles inhibited the acidification process of vegetable liquid. Figure $8 \mathrm{~b}$ shows that all mineral liquid samples possessed low acid level values during aging period, and the acid value of each sample did not exceed $0.05 \mathrm{mg}(\mathrm{KOH}) / \mathrm{g}$. The high concentration of $\mathrm{C}_{60}$ modified mineral liquid showed relatively low acid value. 

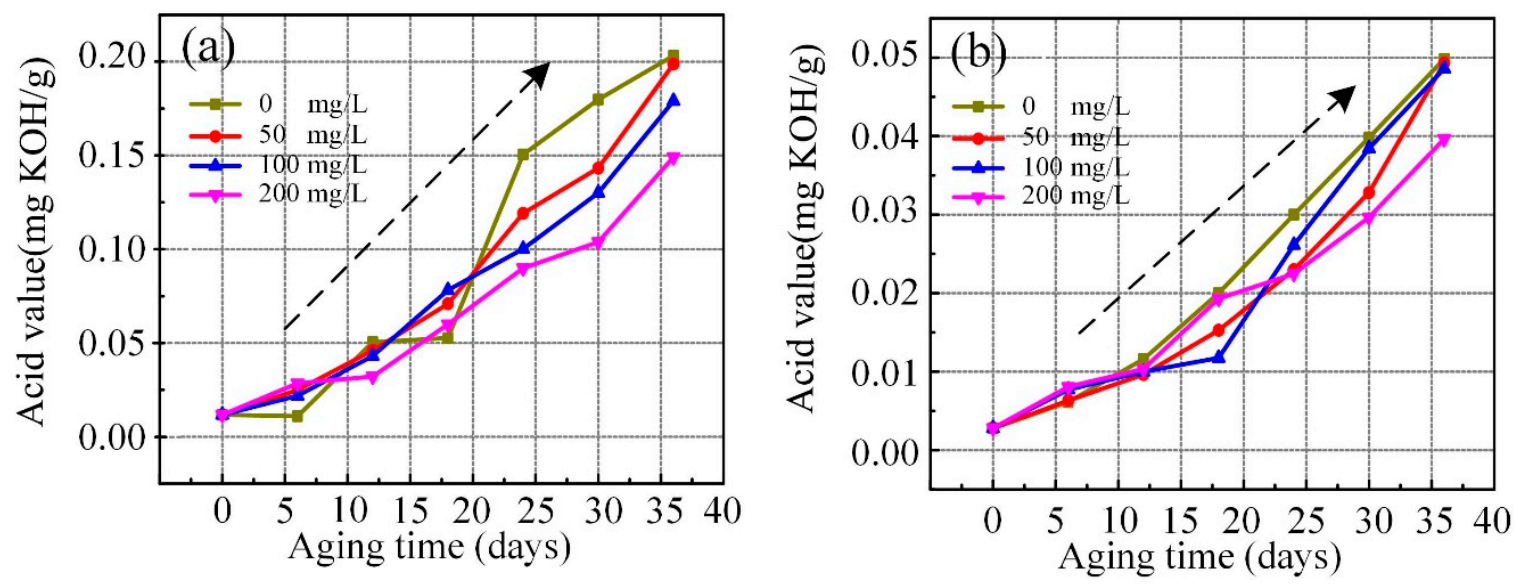

Figure 8. The variation of acid with $\mathrm{C}_{60}$ concentration of aging vegetable insulating liquid (a) and aging mineral liquid (b).

\subsection{Thermal Analysis of Aged Nanofluid}

Quality variation is often observed when transferring materials in the heating process. The thermogravimetric analysis (TGA) tests the temperature control procedures and shows the relationship between the quality of the sample and test temperature. Differential thermal analysis (DTA), which reflects the endothermic and exothermic reactions of the test sample during the increase in temperature, is also measured. Owing to the deterioration of insulating liquid due to oxygen, $100 \mathrm{mg} / \mathrm{L}$ concentration of nanofluid was measured with nitrogen and air. The thermal analysis of $\mathrm{C}_{60}$ modified vegetable insulating liquid was carried out because the deterioration of insulating liquid was due to oxygen. The increase in temperature rate was $10^{\circ} \mathrm{C} / \mathrm{min}$, and the flow rate of the atmosphere (nitrogen and air) was $50 \mathrm{~mL} / \mathrm{min}$. The $\mathrm{C}_{60}$ concentration of modified liquid was $100 \mathrm{mg} / \mathrm{L}$, and each of the samples had been dried prior to the experiment. Thermal analysis provides two kinds of curves, namely, TGA and DTA.

Figure 9a shows the thermal analysis curves of the samples in the nitrogen atmosphere. The results show that both curves of nanofluid and pure liquid have similar changes. Each sample achieved maximum weight loss rate at nearly $415^{\circ} \mathrm{C}$, and maximum endothermic peak appeared at nearly $422^{\circ} \mathrm{C}$. All samples with or without $\mathrm{C}_{60}$ have identical thermal stability in the nitrogen atmosphere. Figure $9 \mathrm{~b}$ shows the thermal analysis curves when the atmosphere is changed to air. The $\mathrm{C}_{60}$ modified liquid showed maximum weight loss rate earlier than the pure liquid, and maximum endothermic peak equally occurred in advance.
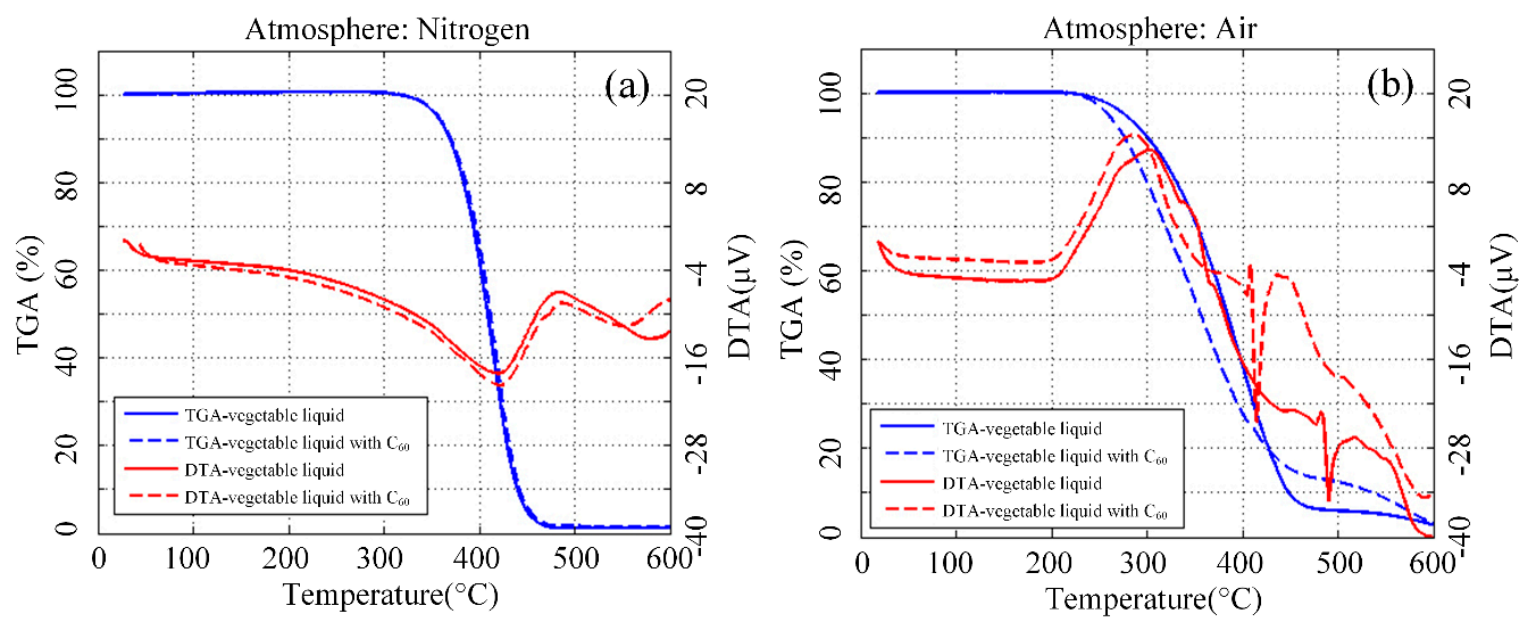

Figure 9. TGA and DTA curve of $\mathrm{C}_{60}$ modified vegetable insulating liquid and its pure sample in nitrogen (a) and air (b) atmosphere. 
Figure 10 shows the thermal analysis curve of modified mineral liquid and pure liquid. In the presence of oxygen, the thermal analysis curves of nanofluid and pure liquid had a high degree of coincidence, with the maximum rate of weight loss which appeared near $220^{\circ} \mathrm{C}$ and the maximum endothermic peak near $215^{\circ} \mathrm{C}$. This result shows that carbon has a slight effect on the thermal stability of mineral liquid.
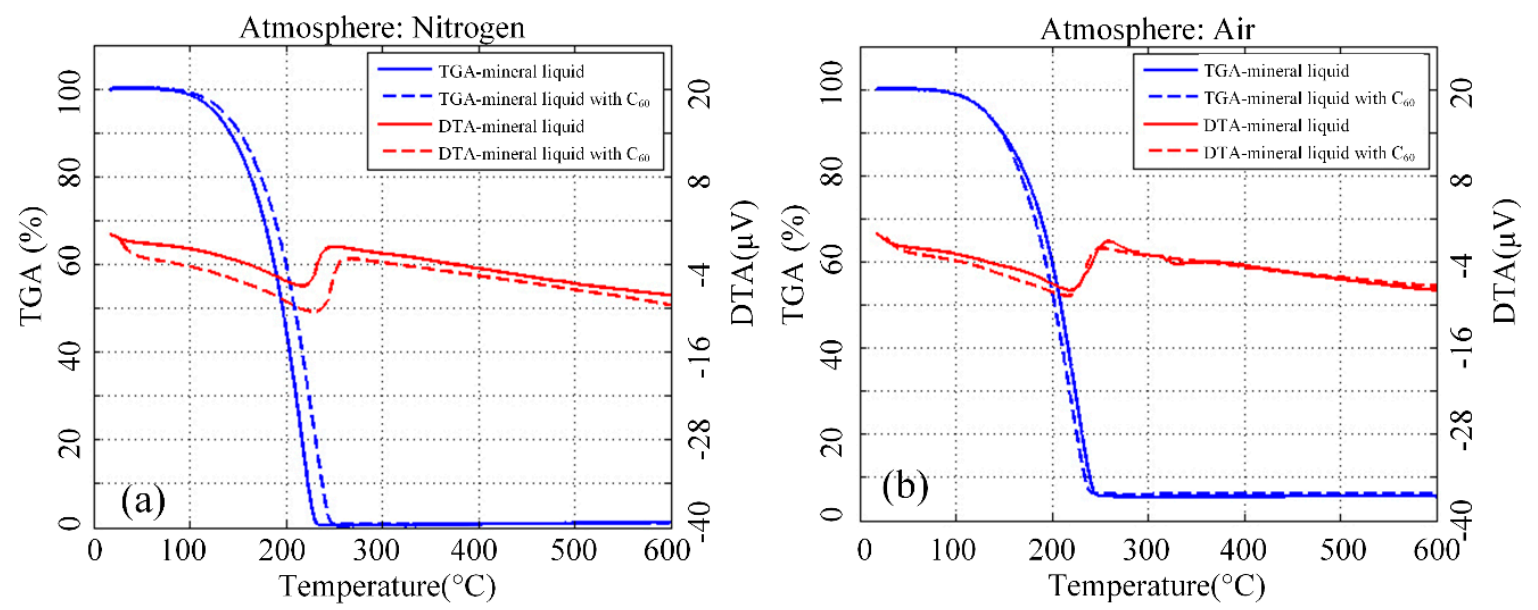

Figure 10. TGA and DTA curve of $\mathrm{C}_{60}$ modified mineral insulating liquid and pure sample nitrogen (a) and air (b) atmosphere.

\subsection{Dissolved Gas Analysis of Aged Nanofluid}

A few flammable gases, which were mostly dissolved in liquid, were generated when the insulation liquid was exposed to unusual thermal and electric fields in the transformer. The oil dissolved gas analysis (DGA) technology was used to effectively detect early failures within the transformer. This study investigated the gas production law of $\mathrm{C}_{60}$ modified insulating liquid, which accelerated thermal aging at $130{ }^{\circ} \mathrm{C}$ for $24 \mathrm{~h}$ in nitrogen.

Figure 11 shows the value of gas dissolved in pure vegetable liquid and nano vegetable liquid sample after thermal aging, respectively. The value of $\mathrm{C}_{60}$ modified vegetable liquid was lower than the pure sample, because the $\mathrm{C}_{60}$ nanoparticles inhibited the thermal decomposition of vegetable insulating liquid, thereby strengthening thermal stability.

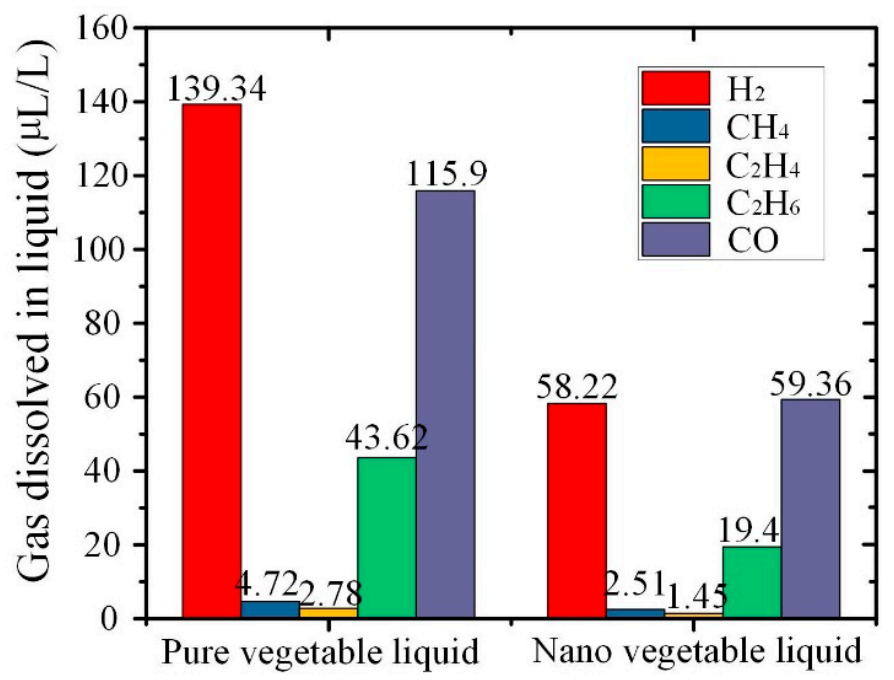

Figure 11. Dissolved gases of vegetable insulating liquid after thermal aging. 
Figure 12 shows the mechanism of anti-oxidation behavior of fullerene. $C_{60}$ is expected to vanish radicals in the fluid under high temperatures by attaching radicals with double bonds on surface. In our previous study, it was confirmed that the vegetable fluid generated various radicals during thermal decomposition [39]. The fullerene with great ability of anti-oxidation can reduce the amounts of radicals, such as the $\mathrm{C}_{3} \mathrm{H}_{5} \bullet$ formed during the initial thermal decomposition of vegetable liquid and the $\mathrm{H} \bullet$ generated for dissolved hydrogen in vegetable liquid. Thus, with the aid of fullerene, the thermal decomposition and hydrogen generation in vegetable liquid under high temperature can be inhibited greatly. The mechanism proposed corresponds to the dissolved gases vegetable liquid after thermal aging as shown in Figure 11.
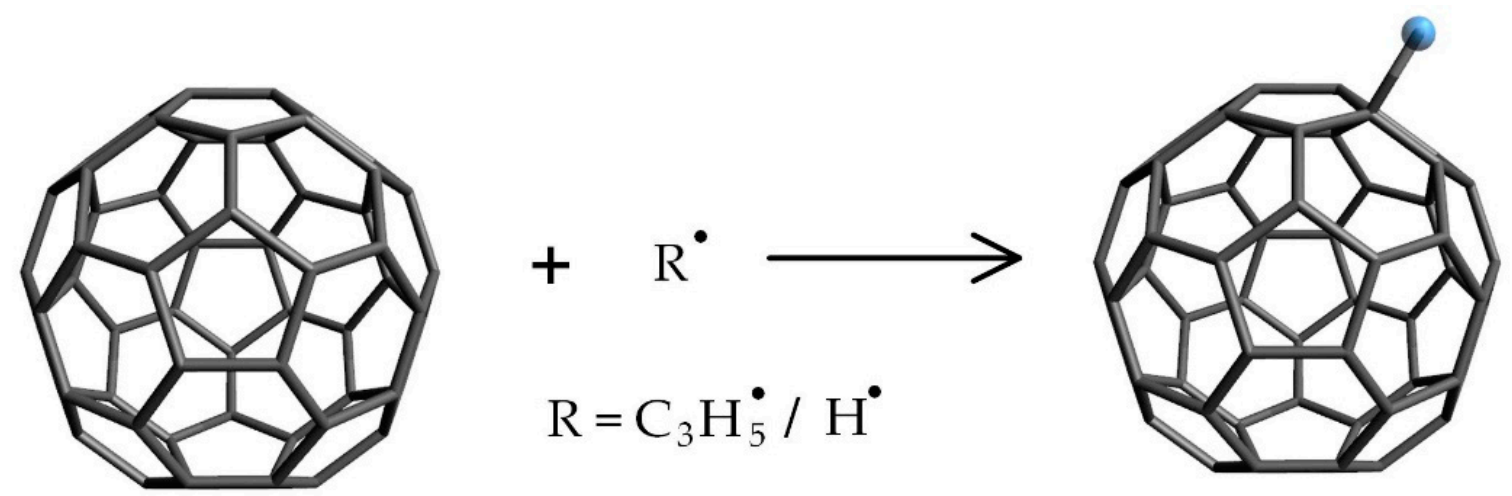

Figure 12. The mechanism of the anti-oxidation behavior of fullerene.

Figure 13 shows the electron density distribution on $\mathrm{C}_{60}$ and the sketch figure for attracted electrons. The zones with blue colors stand for the positively charged area. The negative charge locates in the red area. The deeper color stands for greater electron density. It is observed that the positive charge locates in the core and on surfaces of the fullerene, and the negative charge locates around the positively charged area on surface of the fullerene. The electrons in the fluid under electrical stress are absorbed on surface of the fullerene by the positively charged area as shown in Figure 13. The reduced carrier concentration in the fluid leads to enhanced electrical performances including the breakdown performance, dissipation factor, and electrical resistivity.

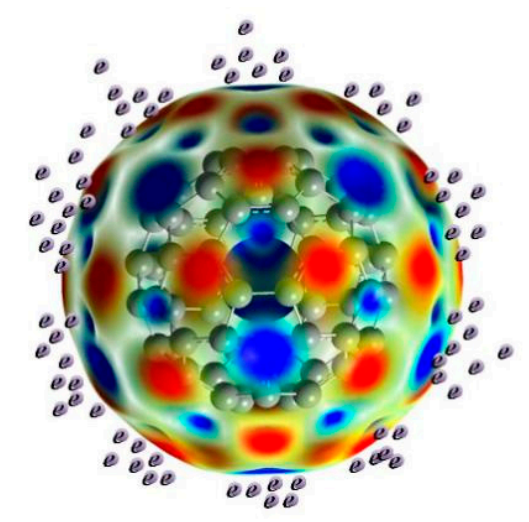

\section{Postively Charged Negatively Charged e Electrons}

Figure 13. The calculation of electron density distribution on fullerene and the sketch figure for attracted electrons. 


\section{Conclusions}

The present work focuses on the electrical properties and thermal stability of vegetable insulating liquid filled with $\mathrm{C}_{60}$ nanoparticles. The experimental and analytical results are concluded as follows:

The surface-modified $\mathrm{C}_{60}$ nanoparticles can be stably dispersed in insulating liquid. The electrical properties, such as dielectric loss factor, electrical resistivity, and breakdown voltage on nanofluids with different concentrations of $\mathrm{C}_{60}$ nanoparticles, were tested. The results showed that $\mathrm{C}_{60}$ nanoparticles enhanced the electrical properties with an optimum concentration of $100 \mathrm{mg} / \mathrm{L}$, in which the dielectric loss factor decreased by $20.1 \%$, electrical resistivity increased by $23.3 \%$, and AC breakdown voltage increased by $8.6 \%$. Meanwhile, the lightning impulse breakdown voltage increased by nearly $8 \%$.

$\mathrm{C}_{60}$ molecules do not possess the capability to accelerate the thermal aging process of insulating liquid. Moreover, vegetable insulating liquid modified by $\mathrm{C}_{60}$ nanoparticles showed good thermal stability under the nitrogen atmosphere. Under the condition of oxygen, the hollow structure of the $\mathrm{C}_{60}$ nanoparticles provides a resident place for oxygen molecules, thereby resulting in the rapid deterioration of modified vegetable insulating liquid at the beginning of thermal aging. However, in the later stage of thermal aging, dielectric loss factor, volume resistivity, and the acid value level were improved compared to the pure liquid sample.

Author Contributions: Conceptualization, Z.H., and J.L.; methodology, F.W.; validation, J.Z.; formal analysis, W.Y.; investigation, Q.W.; resources, J.L.; data curation, K.S.; writing—original draft preparation, Z.H.; writing-review and editing, R.Z.; visualization, Z.H., and Z.L; supervision, J.L.; project administration, Z.H.; funding acquisition, J.L.

Funding: This research was partially funded by National Natural Science Foundation of China (No. 51425702 and No. 51707016), the Science and Technology Project of SGCC (SGTYHT/14-JS-188), the Science and Technology Project of State Grid Chongqing Electric Power Company(2017 Yudian technology 16\#), National Key Basic Research Program of China (973 Program) (2015CB251003), the 111 Project of the Ministry of Education, China (B08036), the Special Funding for China Postdoctoral Science Foundation (No. 2018T110944), the "artificial intelligence" key project of Chongqing (No. cstc2017rgzn-zdyfX0030), the Key Research and Development program of Chongqing about Key Technological Innovation in Industries, 1026223532180165.

Conflicts of Interest: The authors declare no conflict of interest.

\section{References}

1. Romann, T.; Oll, O.; Pikma, P.; Kirsimäe, K.; Lust, E. 4-10 V Capacitors With Graphene-Based Electrodes and Ionic Liquid Electrolyte. J. Power Sources 2015, 280, 606-611. [CrossRef]

2. Dinh Tiep, D.; My, B.N.; Tuan, V.Q.; Thinh, P.Q.; Cuong, T.M.; Tung, B.T.; Trinh, C.D. Tilt sensor based on three electrodes dielectric liquid capacitive sensor. In Proceedings of the 2016 IEEE 6th International Conference on Communications and Electronics, Ha Long Bay, Vietnam, 27-29 July 2016; pp. 172-175. [CrossRef]

3. Hosier, I.L.; Koilraj, J.E.A.; Vaughan, A.S. Effect of Aging on the Physical, Chemical and Dielectric Properties of Dodecylbenzene Cable Oil. In Proceedings of the 2016 IEEE International Conference on Dielectrics (ICD), Montpellier, France, 3-7 July 2016; Volume 23, pp. 3389-3396. [CrossRef]

4. Ravulapalli, S.; Kunta, R.; Ramamoorty, M. Preparation, characterization and feasibility analysis of methyl ester of Sesbania seeds oil (MESSO) as alternate liquid dielectrics in distribution transformers. RSC Adv. 2019, 9, 3311-3319. [CrossRef]

5. Junaid, M.; Xiang, B.; Wang, J.; Liu, Z.; Geng, Y. Experimental Test of Superconductor Fault-Current Switchgear Using Liquid Nitrogen as the Insulation and Arc-Quenching Medium. IEEE Trans. Appl. Supercond. 2019, 29, 1-4. [CrossRef]

6. Dix, L.; McShane, C.P.; Moore, H.R.; Moore, S.; Murphy, J.; Prevost, T.; Smith, S.D. Progress report on natural esters for distribution and power transformers. In Proceedings of the IEEE Power Engineering Society Transmission and Distribution Conference, Calgary, AB, Canada, 26-30 July 2006; pp. 15-17. [CrossRef]

7. Islam, S.; Hossain, M.S.; Reza, M.F.; Rashid, M.M. Experimental Investigation of Insulating Properties of Vegetable Oil under High Voltage. Eur. J. Eng. Res. Sci. 2019, 4, 17-23. [CrossRef]

8. Wang, Y.; Wang, F.; Li, J.; Liang, S.; Zhou, J. Electronic properties of typical molecules and the discharge mechanism of vegetable and mineral insulating oils. Energies 2018, 11, 523. [CrossRef] 
9. Singha, S.; Asano, R., Jr.; Frimpong, G.; Claiborne, C.; Cherry, D. Comparative aging characteristics between a high oleic natural ester dielectric liquid and mineral oil. IEEE Trans. Dielectr. Electr. Insul. 2014, 21, 149-158. [CrossRef]

10. Raymon, A.; Sakthibalan, S.; Cinthal, C.; Subramaniaraja, R.; Yuvaraj, M. Enhancement and comparison of nano-ester insulating fluids. IEEE Trans. Dielectr. Electr. Insul. 2016, 23, 892-900. [CrossRef]

11. Jin, H.; Andritsch, T.; Tsekmes, I.A.; Kochetov, R.; Morshuis, P.H.F.; Smit, J.J. Properties of mineral oil based silica nanofluids. IEEE Trans. Dielectr. Electr. Insul. 2014, 21, 1100-1108. [CrossRef]

12. Dhar, P.; Katiyar, A.; Maganti, L.S.; Pattamatta, A.; Das, S.K. Superior dielectric breakdown strength of graphene and carbon nanotube infused nano-oils. IEEE Trans. Dielectr. Electr. Insul. 2016, 23, 943-956. [CrossRef]

13. Fal, J.; Mahian, O.; Żyła, G. Nanofluids in the Service of High Voltage Transformers: Breakdown Properties of Transformer Oils with Nanoparticles, a Review. Energies 2018, 11, 2942. [CrossRef]

14. Rabinovich, A.; Raj, K.; Nattrass, D.; Hjortsberg, A.; Segal, V. AC (60 Hz) and Impulse Breakdown Strength of a Colloidal Fluid Based on Transformer Oil and Magnetite Nanoparticles. In Proceedings of the 1998 IEEE International Symposium on Electrical Insulation (Cat. No.98CH36239), Arlington, VA, USA, 7-10 June 1998; Volume 2, pp. 619-622. [CrossRef]

15. Zeng, J.; Xuan, Y. Tunable full-spectrum photo-thermal conversion features of magnetic-plasmonic $\mathrm{Fe}_{3} \mathrm{O}_{4} / \mathrm{TiN}$ nanofluid. Nano Energy 2018, 51, 754-763. [CrossRef]

16. Kopčanský, P.; Marton, K.; Tomčo, L.; Koneracká, M.; Timko, M.; Potočová, I.; Herchl, F. The DC- and AC-dielectric breakdown strength of magnetic fluids based on transformer oil. Magnetohydrodynamics 2005, 41, 391-395. [CrossRef]

17. Chen, M.; Zhong, Y.; Lv, Y.; Zhou, Y.; Zhang, S.; Du, Y.; Li, C.; Chen, L. Insulating properties and charge characteristics of natural ester fluid modified by $\mathrm{TiO}_{2}$ semiconductive nanoparticles. IEEE Trans. Dielectr. Electr. Insul. 2013, 20, 135-140. [CrossRef]

18. Li, J.; Du, B.; Wang, F.; Yao, W.; Yao, S. The effect of nanoparticle surfactant polarization on trapping depth of vegetable insulating oil-based nanofluids. Phys. Lett. Sect. A Gen. At. Solid State Phys. 2016, 380, 604-608. [CrossRef]

19. Zhong, Y.; Zhou, J.; Chen, M.; Li, C.; Du, Y.; Li, X.; Zhou, Y.; Lv, Y. Effect of semiconductive nanoparticles on insulating performances of transformer oil. IEEE Trans. Dielectr. Electr. Insul. 2012, 19, 770-776. [CrossRef]

20. Stockton, D.P.; Bland, J.R.; McClanahan, T.; Wilson, J.; Harris, D.L.; McShane, P. Natural Ester Transformer Fluids: Safety, Reliability \& Environmental Performance. In Proceedings of the 2007 IEEE Petroleum and Chemical Industry Technical Conference, Calgary, AB, Canada, 17-19 September 2007; pp. 1-7. [CrossRef]

21. Liao, R.-J.; Sun, C.-X.; Li, J.; Zou, P.; Zhang, Z.-T. Dielectric Properties and Electrodynamic Process of Natural Ester-Based Insulating Nanofluid. Mod. Phys. Lett. B 2011, 25, 2021-2031. [CrossRef]

22. Semenov, K.N.; Charykov, N.A.; Murin, I.V.; Pukharenko, Y.V. Physico-chemical properties of the $\mathrm{C}_{60}$-tris-malonic derivative water solutions. J. Mol. Liq. 2015, 201, 50-58. [CrossRef]

23. Spicer, P.P.; Tran, L.A.; Sitharaman, B.; Mikos, A.G.; Shi, X.; Rusakova, I.; Wilson, L.J. Injectable in situ cross-linkable nanocomposites of biodegradable polymers and carbon nanostructures for bone tissue engineering. J. Biomater. Sci. Polym. Ed. 2007, 18, 655-671. [CrossRef]

24. Yoo, J.; Jeong, J.; Jung, K.; Hyun, G.; Kim, M.; Lee, H.; Yi, Y. Electronic structure of Ba(OH) ${ }_{2}$ interface in inverted organic photovoltaics: Improved electron transport by charged state of $\mathrm{C}_{60}$. Appl. Surf. Sci. 2019, 476, 435-441. [CrossRef]

25. Omacrsawa, E. Perspectives of Fullerene Nanotechnology; Springer Science \& Business Media: Chiba, Japan, 2012; ISBN 978-94-010-9600-3.

26. Lalwani, G.; Sitharaman, B. Multifunctional Fullerene- and Metallofullerene-Based Nanobiomaterials. Nano Life 2013, 3, 1342003. [CrossRef]

27. Aksamit, P.; Zmarzły, D. Dielectric properties of Fullerene-doped insulation liquids. In Proceedings of the 2009 IEEE Conference on Electrical Insulation and Dielectric Phenomena, Virginia Beach, VA, USA, 18-21 October 2009; pp. 212-215.

28. Aksamit, P.; Zmarzły, D.; Boczar, T.; Szmechta, M. Aging properties of fullerene doped transformer oils. In Proceedings of the 2010 IEEE International Symposium on Electrical Insulation, San Diego, CA, USA, 6-9 June 2010; pp. 1-4. [CrossRef] 
29. Boczar, T.; Zmarzły, D.; Aksamit, P.; Lorenc, M. Electrostatic properties of fullerene-doped hydrocarbons. In Proceedings of the International Symposium on Electrical Insulating Materials, Mie, Japan, 7-11 September 2008; pp. 295-298. [CrossRef]

30. Li, J.; Zhang, Z.; Zou, P.; Grzybowski, S.; Zahn, M. Preparation of a vegetable oil-based nanofluid and investigation of its breakdown and dielectric properties. IEEE Electr. Insul. Mag. 2012, 28, 43-50. [CrossRef]

31. Kuzmany, H.; Winkler, R.; Pichler, T. Infrared spectroscopy of fullerenes. J. Phys. Condens. Matter 1995, 7, 6601-6624. [CrossRef]

32. Vassallo, A.M.; Pang, L.S.K.; Cole-Clarke, P.A.; Wilson, M.A. Emission FTIR study of C60 thermal stability and oxidation. J. Am. Chem. Soc. 1991, 113, 7820-7821. [CrossRef]

33. Patterson, A.L. The scherrer formula for X-ray particle size determination. Phys. Rev. 1939, 56, $978-982$. [CrossRef]

34. Rao, A.M.; Bi, X.-X.; Amster, I.J.; Hager, G.T.; Eklund, P.C.; Holden, J.M.; Wang, Y.; Cornett, D.S.; Lee, W.-T.; Zhou, P.; et al. Photoinduced Polymerization of Solid C60 Films. Science. 1993, 955-957. [CrossRef]

35. Hwang, J.G.; O'Sullivan, F.; Zahn, M.; Hjortstam, O.; Pettersson, L.A.A.; Liu, R. Modeling of streamer propagation in transformer oil-based nanofluids. In Proceedings of the 2008 Annual Report Conference on Electrical Insulation and Dielectric Phenomena, Quebec, QC, Canada, 26-29 October 2008; pp. 361-366.

36. Liu, R.; Hjortstam, O.; Hwang, J.G.; Pettersson, L.A.A.; Zahn, M.; O'Sullivan, F.M. Effects of nanoparticle charging on streamer development in transformer oil-based nanofluids. J. Appl. Phys. 2010, 107, 014310. [CrossRef]

37. Zou, P.; Li, J.; Liao, R.-J.; Zhang, Z.-T.; Du, B. Lightning Impulse Breakdown Characteristics and Electrodynamic Process of Insulating Vegetable Oil-Based Nanofluid. Mod. Phys. Lett. B 2012, 26, 1250095. [CrossRef]

38. Du, B.X.; Li, X.L. Dielectric and thermal characteristics of vegetable oil filled with BN nanoparticles. IEEE Trans. Dielectr. Electr. Insul. 2017, 24, 956-963. [CrossRef]

39. Xiang, C.; Zhou, Q.; Li, J.; Huang, Q.; Song, H.; Zhang, Z. Comparison of Dissolved Gases in Mineral and Vegetable Insulating Oils under Typical Electrical and Thermal Faults. Energies 2016, 9, 312. [CrossRef]

(C) 2019 by the authors. Licensee MDPI, Basel, Switzerland. This article is an open access article distributed under the terms and conditions of the Creative Commons Attribution (CC BY) license (http://creativecommons.org/licenses/by/4.0/). 